\title{
BMJ How can socioeconomic inequalities Open in hospital admissions be explained? A cohort study
}

\author{
Gerry McCartney, ${ }^{1}$ Carole Hart, ${ }^{2}$ Graham Watt ${ }^{2}$
}

To cite: McCartney G, Hart C, Watt G. How can socioeconomic inequalities in hospital admissions be explained? A cohort study. BMJ Open 2013;3:e002433. doi:10.1136/bmjopen-2012002433

- Prepublication history and additional material for this paper is available online. To view these files please visit the journal online (http://dx.doi.org/10.1136/ bmjopen-2012-002433).

Received 22 December 2012 Revised 3 July 2013 Accepted 15 July 2013

${ }^{1}$ NHS Health Scotland, Glasgow, Scotland, UK ${ }^{2}$ Institute of Health and Wellbeing, University of Glasgow, Glasgow, UK

Correspondence to Dr Gerry McCartney; gmccartney@nhs.net

\section{ABSTRACT}

Objectives: To investigate which antecedent risk factors can explain the social patterning in hospital use.

Design: Prospective cohort study with up to 37 years of follow-up.

Setting: Representative community sample in the West of Scotland.

Participants: 7049 men and 8353 women aged 45-64 years were recruited into the study from the general population between 1972 and 1976 (78\% of the eligible population).

\section{Primary and secondary outcome measures:}

Hospital admissions and bed days by cause and by classification into emergency or non-emergency.

Results: All-cause hospital admission rate ratios (RRs) were not obviously socially patterned for women (RR $1.04,95 \% \mathrm{Cl} 0.98$ to 1.10) or men (RR 1.0, 95\% Cl 0.94 to 1.06) in social classes IV and V compared with social classes I and II. However, cardiovascular disease, coronary heart disease and stroke in women, and respiratory disease for men and women were socially patterned, although this attenuated markedly with the addition of baseline risk factors. Hospital bed days were generally socially patterned and the differences were largely explained by baseline risk factors. The overall RRs of mental health admissions in contrast were socially patterned for women (RR 1.77, 95\% Cl 1.38 to 2.27) and men (RR 1.51, 95\% Cl 1.11 to 2.06) in social classes IV and V compared with social classes I and II, but the pattern did not attenuate with the addition of baseline risk factors. Emergency hospital admissions were associated with lower social class, but there was an inverse relationship for non-emergency hospital admissions.

Conclusions: Overall admissions to hospital were only marginally socially patterned, and less than would be expected on the basis of the gradient in baseline risk. However, there was marked social patterning in admissions for mental health problems. Non-emergency hospital admissions were patterned inversely according to risk. Further work is required to explain and address this inequitable gradient in healthcare use.

\section{INTRODUCTION}

Julian Tudor Hart famously stated, "The availability of good medical care tends to

\section{ARTICLE SUMMARY}

\section{Article focus}

- Are there gradients in emergency and nonemergency hospital use by social class, and to what extent is this explained by pre-existing risk factors?

\section{Key messages}

- Overall hospital admissions are only marginally socially patterned and less than would be expected on the basis of baseline risk.

- Emergency hospital admissions and admissions for mental health conditions are much higher in social classes IV and V compared with social classes I and II.

- Attention is required to explain and address the inverse gradient in non-emergency admissions.

Strengths and limitations of this study

- This cohort study has up to 37 years of follow-up, includes women and men and is representative of deprived as well as affluent communities.

- The baseline risk factors were collected at one point in time and may have since changed, potentially biasing the potential explanatory power of the baseline risks towards the null.

vary inversely with the need for it in the population served. This inverse care law operates more completely where medical care is most exposed to market forces, and less so where such exposure is reduced."

Scotland, in common with the rest of the $\mathrm{UK}$, provides most healthcare services free at the point of need through the National Health Service (NHS), including the use of hospital inpatient services. In theory, therefore, the NHS model in Scotland provides no barriers to the equitable use of health services, based on need.

However, planning the distribution of health service resources and ensuring that the use of services is equitable is complicated. Without epidemiological data, information on unmet need is absent, and can 
only be inferred from data on health service demand (ie, use). ${ }^{2}$

In the NHS, there are two routes through which a patient can get admitted to hospital. The first is as an unplanned emergency admission through selfpresentation at an accident or emergency department, an emergency ambulance transfer or by referral from a general practitioner (GP or family doctor). Alternatively, non-emergency hospital admission can be planned in advance through a hospital outpatients department appointment or by arrangement through the GP, for example, for a hip replacement operation.

Higher hospital admission rates have been associated with lower socioeconomic status in Amsterdam (for psychiatric admissions), ${ }^{3}$ New Zealand (for general and psychiatric admissions), ${ }^{4}$ and for Australia, ${ }^{5}$ Norway ${ }^{6}$ and London $^{7}$ (for general hospital admissions), although the patterning is less clear in Italy, ${ }^{8-10}$ Canada $^{11}{ }^{12}$ and the USA. ${ }^{13}{ }^{14}$ Where longitudinal data are available, antecedent morbidity or risk factors can explain part of this patterning (as lower socioeconomic status is associated with greater healthcare needs). ${ }^{9} 13 \quad 14$ Although admissions are often higher among those with lower socioeconomic status, there is evidence that those of lower socioeconomic status also have shorter hospital stays and fewer planned admissions, ${ }^{4} 711$ suggesting an inverse care law. The difference in social patterning of emergency and planned hospital admissions, as well as the relation to underlying need, is not fully understood.

If the NHS is to provide an equitable service, the use of hospital inpatient services should be in proportion to need. This would suggest that general and mental health admissions, and emergency and non-emergency admissions should display a gradient across social class since mortality and morbidity, as crude markers of health need, are known to increase from social class I through to social class $\mathrm{V}^{15}{ }^{16}$ Furthermore, much of the class gradient is likely to be explained by other markers of healthcare need, including antecedent morbidity and known risk factors.

This proposition was tested using data from a cohort study in the West of Scotland to evaluate the social patterning of hospitalisation rates and bed days, the extent to which these are explained by available baseline cardiovascular risk factors, and whether this varies between general and mental health admissions or between emergency and non-emergency admissions. Our hypothesis was that there would be a social class gradient in hospital admissions and bed days, but that this would be explained by pre-existing behavioural, anthropometric, biological and clinical risk factors.

\section{METHODS}

We used data from the Renfrew and Paisley prospective cohort study, which was initiated between 1972 and 1976 and is described in detail elsewhere. ${ }^{17}$ Briefly, men and women aged 45-64 years who were resident in these two towns in the West of Scotland completed a questionnaire and attended a health screening examination. There were 7049 men and 8353 women in the study, which amounted to a response rate of $78 \%$ in the eligible population. Self-reported data were collected about smoking habit, diabetes, bronchitis, angina and occupation. Bronchitis was defined as having persistent and infective phlegm and being breathless (from the Medical Research Council (MRG) questionnaire), ${ }^{17}$ angina was derived from the Rose Angina Questionnaire, with angina defined as 'definite', 18 and social class was derived from the Registrar General's classification of occupations. ${ }^{19}$ The social class of women was based on their own occupation, except for housewives who took the social class of their husbands. At the screening examination, blood pressure and FEV1 were measured by trained staff, a non-fasting blood sample was taken for measurement of plasma cholesterol, an ECG was taken from which ischaemia was defined, and height and weight were measured from which body mass index (BMI) in $\mathrm{kg} / \mathrm{m}^{2}$ was derived. These clinical, biological and anthropometric baseline characteristics were socially patterned. ${ }^{17} 20$

Participants were followed up for mortality by flagging with the NHS Central Register, and death information was received in the follow-up period from screening to the end of 2009. Information was also received when participants left the UK. Person-years were calculated from date of screening to date of death, date of embarkation or the end of 2009 as appropriate. A computerised linkage was made with hospital discharge records in Scotland (Scottish Morbidity Records (SMRs)). ${ }^{21}$ They will be referred to as admissions in this paper. The Privacy Advisory Committee of NHS Scotland Information Services gave permission for the linked data to be used. General hospital admissions (SMR1) and mental health admissions (SMR4) were obtained from the date of screening to the end of 2009. As geriatric long-stay admissions (involving admissions to NHS facilities, not private nursing or care homes) were only available for part of the follow-up period due to changes in recording procedures, they were excluded from this study. Numbers of general admissions were added for each participant, with transfer admissions (where the hospital stay included transfers to other specialties) not counted. Bed days were calculated by subtracting the date of admission from the date of discharge and adding one (to ensure that day cases were not lost). For transfer admissions, the one was not added to ensure against double counting. Emergency general hospital admissions were identified by a code; all other general hospital admissions were defined as non-emergency.

Admissions and bed days were also calculated for different causes of general hospital admission: cardiovascular disease (CVD), coronary heart disease (CHD), stroke, respiratory diseases, digestive diseases and cancers. For mental health admissions, SMR1 (relating to general hospitals) admissions with mental health 
codes and all SMR4 (relating to mental health hospitals) admissions were used. Mental health admissions were also subdivided into these different causes: depression/ anxiety, psychoses, drug and alcohol dependence, and Alzheimer's disease and dementia. For the analyses for specific causes, only the first diagnostic coding was included. The International Classification of Diseases (ICD) codes for the different causes are given in web table 1 .

Excluded from the study were 23 participants (9 men and 14 women) who were lost to follow-up and 423 participants (72 men and 351 women) with missing data on social class, leaving 14956 participants (6968 men and 7988 women) in the analysis. Negative binomial regression analysis was used to calculate the rate ratio for admissions and bed days by social class in four groups (I and II, III non-manual (IIINM), III manual (IIIM), IV and V), using STATA V.10. Analyses were first adjusted for age, and then further adjusted for the following risk factors measured at baseline: systolic blood pressure, cholesterol, BMI, height, FEV1, angina, ischaemic ECG, bronchitis, smoking and diabetes.

\section{RESULTS}

\section{Hospital admissions by social class}

Tables 1 and 2 show the patterning of general hospital admissions and the number of bed days by social class. Overall, the admission rates to hospital for all causes together are not obviously socially patterned for men or women, with an admission rate ratio of 1.04 (95\% CI 0.98 to 1.10) for women in social classes IV and V compared with social classes I and II and a rate ratio of 1.0 (95\% CI 0.94 to 1.06) for men. Although there was no social patterning for overall hospital admissions, a steep social gradient was present for respiratory causes in women and men which attenuated markedly with the addition of the baseline risk factors into the model. Social patterning was also seen for CVD, CHD and stroke in women, all of which attenuated with the addition of the baseline risk factors, but was not obvious for men. There was no clear social patterning of admissions for digestive causes or cancer.

In contrast to the patterning of hospital admissions, the number of bed days for all causes was socially patterned. In women, the rate ratios were 1.07 (95\% CI 0.98 to 1.17 ) for social class IIINM, 1.15 (95\% CI 1.05 to 1.27 ) in social class IIIM and 1.11 (95\% CI 1.03 to 1.21 ) in social classes IV and V. These differences attenuated markedly with the addition of the baseline risk factors. Similarly, the bed days were socially patterned in men, with a rate ratio of 1.06 (95\% CI 0.94 to 1.19 ) in social class IIINM, 1.09 (95\% CI 1.0 to 1.19$)$ in social class IIIM and 1.13 (95\% CI 1.02 to 1.23) in social classes IV and $\mathrm{V}$, which again attenuated markedly with the addition of the baseline risk factors to the model. Social patterning in the rate ratios was evident for CVD and CHD in women, and for respiratory disease for men and women, all of which attenuated markedly with the addition of baseline risk factors. In contrast, there was no clear social patterning for the number of bed days for stroke, digestive causes or cancer.

\section{Mental health hospital admissions by social class}

Tables 3 and 4 show the rate ratios for mental health hospital admissions by social class for women and men (approximately $80 \%$ of which were recorded on the SMR4 through psychiatric hospitals). Overall, admissions and bed days were higher among the lower social classes for women and men. This patterning attenuated slightly with the addition of baseline risk factors in women but still remained significant (for admissions), and attenuated more in men. The social patterning of admissions was particularly marked for psychoses (with a rate ratio for admissions in women of 2.82 and in men of 1.84 in social classes IV and V compared with social classes I and II) and drug-related and alcohol-related admissions in men (with a rate ratio of 3.23 in social classes IV and V compared with social classes I and II). In men, the social patterning of bed days for psychosis was even more marked with a rate ratio of 6.15 in social classes IV and V compared with social classes I and II. Admissions to hospital for Alzheimer's and dementia were socially patterned for women and men, but the number of bed days was patterned only among men. There was a suggestion of an inverse social patterning (ie, higher admission rates among social classes I and II) for drugs and alcohol in women and depression in men, but the rate ratio estimates were imprecise because of the small numbers of admissions. The addition of the baseline risk factors did not substantially help explain the overall social patterning of admissions or bed days, or for specific causes, for women or men with the exception of drug-related and alcohol-related admissions in men where the baseline risk explained over half of the excess in social classes IV and V.

\section{Emergency and non-emergency hospital admissions by social class}

Table 5 shows that the rate ratios of emergency admissions to hospital in women were 1.06 (95\% CI 0.99 to 1.14), 1.10 (95\% CI 1.01 to 1.18 ) and 1.18 (95\% CI 1.11 to 1.26) in social classes IIINM, IIIM, IV and V, respectively, compared with social classes I and II. The higher rate ratios were attenuated with the addition of the baseline risk factors. In contrast, the rate ratios for nonemergency admissions to hospital were 1.03 (95\% CI 0.95 to 1.11 ), 0.95 (95\% CI 0.87 to 1.04 ) and 0.93 (95\% CI 0.86 to 1.0) in social classes IIINM, IIIM, IV and V, respectively, compared with social classes I and II. Again, this social patterning attenuated towards a rate ratio of 1 with the addition of the baseline risk factors to the model.

A similar pattern was seen for men where the rate ratios of emergency admissions to hospital were 1.03 (95\% CI 0.94 to 1.13 ), 1.06 (95\% CI 0.99 to 1.14 ) and 
Table 1 Number of general hospital admissions and bed days by social class and diagnosis in women from the Renfrew and Paisley study

\begin{tabular}{|c|c|c|c|c|}
\hline \multirow{4}{*}{$\begin{array}{l}\text { Number of women } \\
\text { Person-years }\end{array}$} & \multicolumn{4}{|c|}{ Social classes } \\
\hline & I and II & IIINM & IIIM & IV and V \\
\hline & 1451 & 1975 & 1486 & 3076 \\
\hline & 37262 & 50869 & 33980 & 72487 \\
\hline \multicolumn{5}{|l|}{ All causes } \\
\hline Admissions* & 8608 & 12180 (239) & 7928 (233) & $17413(240)$ \\
\hline Rate ratio ${ }_{1}$ & 1 & 1.04 (0.98 to 1.11$)$ & 1.02 (0.95 to 1.09$)$ & $1.04(0.98$ to 1.10$)$ \\
\hline Rate ratio 2 & 1 & $1.04(0.98$ to 1.10$)$ & $0.99(0.93$ to 1.06$)$ & 1.01 (0.95 to 1.07$)$ \\
\hline Bed days $\dagger$ & 2598 & 2800 & 2966 & 2961 \\
\hline Rate ratio 1 & 1 & $1.07(0.98$ to 1.17$)$ & $1.15(1.05$ to 1.27$)$ & 1.11 (1.03 to 1.21$)$ \\
\hline Rate ratio 2 & 1 & 1.06 (0.97 to 1.15$)$ & 1.08 (0.98 to 1.18$)$ & $1.02(0.94$ to 1.11$)$ \\
\hline \multicolumn{5}{|l|}{ CVD } \\
\hline Admissions ${ }^{\star}$ & $1423(38)$ & $2088(41)$ & $1442(42)$ & $3345(46)$ \\
\hline Rate ratio ${ }_{1}$ & 1 & $1.10(0.98$ to 1.24$)$ & 1.11 (0.98 to 1.26$)$ & 1.21 (1.09 to 1.35$)$ \\
\hline Rate ratio 2 & 1 & 1.09 (0.97 to 1.22$)$ & $1.02(0.90$ to 1.15$)$ & 1.10 (0.99 to 1.22$)$ \\
\hline Bed days $\dagger$ & 589 & 601 & 670 & 736 \\
\hline Rate ratio ${ }_{1}$ & 1 & 1.04 (0.86 to 1.26$)$ & 1.13 (0.92 to 1.38$)$ & 1.25 (1.05 to 1.49$)$ \\
\hline Rate ratio 2 & 1 & 0.99 (0.82 to 1.20$)$ & 0.96 (0.78 to 1.17$)$ & 1.02 (0.85 to 1.22$)$ \\
\hline \multicolumn{5}{|l|}{ CHD } \\
\hline Admissions* & $417(11)$ & $531(10)$ & $473(14)$ & $1076(15)$ \\
\hline Rate ratio ${ }_{1}$ & 1 & 0.95 (0.77 to 1.18$)$ & 1.26 (1.01 to 1.57$)$ & 1.34 (1.10 to 1.62$)$ \\
\hline Rate ratio 2 & 1 & 0.95 (0.78 to 1.17$)$ & $1.15(0.93$ to 1.44$)$ & 1.21 (1.0 to 1.47$)$ \\
\hline Bed days $†$ & 111 & 101 & 147 & 149 \\
\hline Rate ratio ${ }_{1}$ & 1 & $1.03(0.74$ to 1.44$)$ & 1.68 (1.17 to 2.41$)$ & 1.44 (1.05 to 1.97$)$ \\
\hline Rate ratio 2 & 1 & 1.06 (0.76 to 1.48$)$ & 1.34 (0.94 to 1.92$)$ & 1.24 (0.91 to 1.70$)$ \\
\hline \multicolumn{5}{|l|}{ Stroke } \\
\hline Admissions* & $262(7)$ & $390(8)$ & $289(9)$ & $681(9)$ \\
\hline Rate ratio ${ }_{1}$ & 1 & 1.09 (0.89 to 1.33$)$ & $1.12(0.91$ to 1.39$)$ & $1.29(1.08$ to 1.55$)$ \\
\hline Rate ratio 2 & 1 & 1.09 (0.90 to 1.33$)$ & $1.05(0.85$ to 1.30$)$ & $1.18(0.98$ to 1.41$)$ \\
\hline Bed days $†$ & 243 & 218 & 287 & 319 \\
\hline Rate ratio 1 & 1 & 0.91 (0.62 to 1.34$)$ & 1.05 (0.70 to 1.60$)$ & 1.31 (0.92 to 1.87$)$ \\
\hline Rate ratio 2 & 1 & 0.92 (0.62 to 1.35$)$ & 0.99 (0.65 to 1.50$)$ & $1.09(0.75$ to 1.58$)$ \\
\hline \multicolumn{5}{|l|}{ Respiratory } \\
\hline Admissions* & $392(11)$ & $625(12)$ & $462(14)$ & $1,207(17)$ \\
\hline Rate ratio ${ }_{1}$ & 1 & 1.15 (0.94 to 1.40$)$ & $1.33(1.07$ to 1.65$)$ & 1.60 (1.33 to 1.92$)$ \\
\hline Rate ratio 2 & 1 & 1.08 (0.89 to 1.30$)$ & 0.98 (0.80 to 1.20$)$ & 1.17 (0.98 to 1.39$)$ \\
\hline Bed days $\dagger$ & 136 & 187 & 195 & 209 \\
\hline Rate ratio 1 & 1 & 1.36 (0.99 to 1.88$)$ & 1.55 (1.10 to 2.19$)$ & 1.60 (1.19 to 2.15$)$ \\
\hline Rate ratio 2 & 1 & 1.23 (0.90 to 1.68$)$ & 0.88 (0.62 to 1.24$)$ & 1.03 (0.76 to 1.38$)$ \\
\hline \multicolumn{5}{|l|}{ Digestive } \\
\hline Admissions* & 1059 (28) & $1497(29)$ & 1079 (32) & $2134(29)$ \\
\hline Rate ratio ${ }_{1}$ & 1 & 1.03 (0.91 to 1.18$)$ & 1.13 (0.98 to 1.29$)$ & 1.02 (0.91 to 1.15$)$ \\
\hline Rate ratio ${ }_{2}$ & 1 & 1.04 (0.91 to 1.18$)$ & $1.10(0.96$ to 1.26$)$ & $0.99(0.87$ to 1.11$)$ \\
\hline Bed days $\dagger$ & 239 & 223 & 296 & 249 \\
\hline Rate ratio $_{1}$ & 1 & $0.92(0.75$ to 1.14$)$ & 1.27 (1.01 to 1.60$)$ & $0.97(0.80$ to 1.18$)$ \\
\hline Rate ratio 2 & 1 & $0.93(0.75$ to 1.15$)$ & 1.19 (0.94 to 1.50$)$ & 0.89 (0.73 to 1.09$)$ \\
\hline \multicolumn{5}{|l|}{ Cancer } \\
\hline Admissions* & $1286(35)$ & 1754 (35) & 1129 (33) & $2179(30)$ \\
\hline Rate ratio ${ }_{1}$ & 1 & 1.07 (0.88 to 1.30$)$ & $1.01(0.82$ to 1.25$)$ & 0.91 (0.76 to 1.09$)$ \\
\hline Rate ratio 2 & 1 & 1.06 (0.87 to 1.28$)$ & 1.01 (0.81 to 1.24$)$ & $0.91(0.76$ to 1.10$)$ \\
\hline Bed days $†$ & 338 & 342 & 376 & 335 \\
\hline Rate ratio ${ }_{1}$ & 1 & 1.07 (0.81 to 1.41$)$ & $1.19(0.88$ to 1.60$)$ & 1.05 (0.81 to 1.36$)$ \\
\hline Rate ratio 2 & 1 & $1.03(0.78$ to 1.36$)$ & $1.16(0.85$ to 1.57$)$ & $0.96(0.74$ to 1.25$)$ \\
\hline
\end{tabular}

${ }^{*}$ Number (per 1000 person-years).

†Per 1000 person-years.

IIIM, III manual; IIINM, III non-manual; CHD, coronary heart disease; CVD, cardiovascular disease; rate ratio ${ }_{1}$, adjusted for age; rate ratio ${ }_{2}$, adjusted for age, systolic blood pressure, cholesterol, body mass index, height, FEV1, angina, ischaemic ECG, bronchitis, smoking and diabetes. 
Table 2 Number of general hospital admissions and bed days by social class and diagnosis in men from the Renfrew and Paisley study

\begin{tabular}{|c|c|c|c|c|}
\hline \multirow{4}{*}{$\begin{array}{l}\text { Number of men } \\
\text { Person-years }\end{array}$} & \multicolumn{4}{|c|}{ Social classes } \\
\hline & I and II & IIINM & IIIM & IV and V \\
\hline & 1329 & 829 & 2814 & 1996 \\
\hline & 30385 & 17036 & 56966 & 38331 \\
\hline \multicolumn{5}{|l|}{ All causes } \\
\hline Admissions* & $8371(276)$ & 4641 (272) & 15605 (274) & $10610(277)$ \\
\hline Rate ratio ${ }_{1}$ & 1 & 0.98 (0.90 to 1.06$)$ & 0.99 (0.93 to 1.05$)$ & 1.0 (0.94 to 1.06$)$ \\
\hline Rate ratio 2 & 1 & 0.98 (0.91 to 1.06$)$ & 0.98 (0.92 to 1.04$)$ & 0.99 (0.93 to 1.06$)$ \\
\hline Bed days $\dagger$ & 2556 & 2728 & 2822 & 2997 \\
\hline Rate ratio ${ }_{1}$ & 1 & $1.06(0.94$ to 1.19$)$ & $1.09(1.0$ to 1.19$)$ & $1.13(1.02$ to 1.23$)$ \\
\hline Rate ratio 2 & 1 & 1.02 (0.91 to 1.15$)$ & $1.02(0.94$ to 1.12$)$ & 1.03 (0.94 to 1.14$)$ \\
\hline \multicolumn{5}{|l|}{ CVD } \\
\hline Admissions* & $1878(62)$ & $952(56)$ & $3286(58)$ & $2163(56)$ \\
\hline Rate ratio ${ }_{1}$ & 1 & $0.90(0.78$ to 1.03$)$ & 0.91 (0.82 to 1.01$)$ & 0.91 (0.81 to 1.02$)$ \\
\hline Rate ratio 2 & 1 & 0.90 (0.78 to 1.03$)$ & $0.90(0.82$ to 1.0$)$ & 0.90 (0.81 to 1.01$)$ \\
\hline Bed dayst & 706 & 725 & 778 & 787 \\
\hline Rate ratio 1 & 1 & 0.98 (0.78 to 1.24$)$ & $1.0(0.84$ to 1.18$)$ & 1.04 (0.87 to 1.25$)$ \\
\hline Rate ratio 2 & 1 & $1.0(0.80$ to 1.26$)$ & 0.95 (0.80 to 1.13$)$ & $1.0(0.83$ to 1.21$)$ \\
\hline \multicolumn{5}{|l|}{$\mathrm{CHD}$} \\
\hline Admissions* & 674 (22) & $353(21)$ & $1253(22)$ & $731(19)$ \\
\hline Rate ratio 1 & 1 & $0.93(0.75$ to 1.17$)$ & 0.98 (0.83 to 1.16$)$ & $0.87(0.73$ to 1.04$)$ \\
\hline Rate ratio 2 & 1 & 0.96 (0.77 to 1.20$)$ & 1.01 (0.86 to 1.19$)$ & 0.93 (0.78 to 1.12$)$ \\
\hline Bed days $†$ & 202 & 200 & 224 & 192 \\
\hline Rate ratio ${ }_{1}$ & 1 & 1.05 (0.73 to 1.51$)$ & 1.02 (0.78 to 1.34$)$ & 0.95 (0.71 to 1.28$)$ \\
\hline Rate ratio 2 & 1 & 1.11 (0.77 to 1.61$)$ & $1.02(0.77$ to 1.34$)$ & 1.05 (0.78 to 1.42$)$ \\
\hline \multicolumn{5}{|l|}{ Stroke } \\
\hline Admissions* & $229(8)$ & $142(8)$ & $533(9)$ & $347(9)$ \\
\hline Rate ratio ${ }_{1}$ & 1 & 1.04 (0.80 to 1.34$)$ & $1.22(1.01$ to 1.48$)$ & 1.14 (0.93 to 1.40$)$ \\
\hline Rate ratio 2 & 1 & $1.01(0.79$ to 1.31$)$ & $1.16(0.96$ to 1.41$)$ & $1.09(0.88$ to 1.34$)$ \\
\hline Bed days $\dagger$ & 177 & 247 & 270 & 266 \\
\hline Rate ratio 1 & 1 & 0.94 (0.56 to 1.59$)$ & $1.21(0.82$ to 1.79$)$ & 1.01 (0.67 to 1.54$)$ \\
\hline Rate ratio 2 & 1 & 1.06 (0.63 to 1.80$)$ & 1.23 (0.83 to 1.83$)$ & $1.20(0.78$ to 1.84$)$ \\
\hline \multicolumn{5}{|l|}{ Respiratory } \\
\hline Admissions* & $403(13)$ & 320 (19) & $1123(20)$ & $853(22)$ \\
\hline Rate ratio 1 & 1 & $1.38(1.10$ to 1.73$)$ & 1.50 (1.26 to 1.78$)$ & 1.73 (1.44 to 2.08$)$ \\
\hline Rate ratio 2 & 1 & $1.20(0.97$ to 1.49$)$ & 1.15 (0.97 to 1.36$)$ & 1.15 (0.96 to 1.37$)$ \\
\hline Bed days $†$ & 153 & 218 & 258 & 305 \\
\hline Rate ratio 1 & 1 & 1.33 (0.91 to 1.93$)$ & 1.85 (1.40 to 2.46$)$ & 1.96 (1.45 to 2.64$)$ \\
\hline Rate ratio 2 & 1 & 1.11 (0.77 to 1.59$)$ & 1.29 (0.98 to 1.71$)$ & 1.29 (0.96 to 1.73 ) \\
\hline \multicolumn{5}{|l|}{ Digestive } \\
\hline Admissions ${ }^{*}$ & $998(33)$ & $623(37)$ & $1789(31)$ & $1233(32)$ \\
\hline Rate ratio 1 & 1 & $1.09(0.94$ to 1.27$)$ & 0.94 (0.83 to 1.05$)$ & 0.97 (0.85 to 1.10$)$ \\
\hline Rate ratio 2 & 1 & 1.09 (0.94 to 1.28$)$ & $0.93(0.82$ to 1.05$)$ & 0.96 (0.84 to 1.09 ) \\
\hline Bed days $\dagger$ & 237 & 320 & 214 & 251 \\
\hline Rate ratio ${ }_{1}$ & 1 & 1.73 (1.32 to 2.26$)$ & 0.85 (0.70 to 1.03$)$ & 0.98 (0.79 to 1.21$)$ \\
\hline Rate ratio 2 & 1 & 1.50 (1.14 to 1.98$)$ & 0.77 (0.63 to 0.94$)$ & 0.88 (0.71 to 1.10$)$ \\
\hline \multicolumn{5}{|l|}{ Cancer } \\
\hline Admissions* & $1428(47)$ & $738(43)$ & $2568(45)$ & $1759(46)$ \\
\hline Rate ratio ${ }_{1}$ & 1 & $0.90(0.72$ to 1.11$)$ & 1.01 (0.86 to 1.19$)$ & 0.94 (0.79 to 1.12$)$ \\
\hline Rate ratio 2 & 1 & 0.90 (0.73 to 1.12$)$ & $1.0(0.85$ to 1.18$)$ & $0.96(0.80$ to 1.15$)$ \\
\hline Bed days $†$ & 358 & 382 & 452 & 474 \\
\hline Rate ratio ${ }_{1}$ & 1 & $0.86(0.63$ to 1.19$)$ & 1.25 (0.98 to 1.59$)$ & 1.14 (0.88 to 1.47$)$ \\
\hline Rate ratio 2 & 1 & 0.86 (0.62 to 1.18$)$ & 1.22 (0.96 to 1.56$)$ & 1.19 (0.92 to 1.56$)$ \\
\hline
\end{tabular}

${ }^{*}$ Number (per 1000 person-years).

†Per 1000 person-years.

IIIM, III manual; IIINM, III non-manual; CHD, coronary heart disease; CVD, cardiovascular disease; rate ratio ${ }_{1}$, adjusted for age; rate ratio ${ }_{2}$, adjusted for age, systolic blood pressure, cholesterol, body mass index, height, FEV1, angina, ischaemic ECG, bronchitis, smoking and diabetes. 
Table 3 Number of mental health admissions and bed days by social class in women from the Renfrew and Paisley study

\begin{tabular}{|c|c|c|c|c|}
\hline \multirow{4}{*}{$\begin{array}{l}\text { Number of women } \\
\text { Person-years }\end{array}$} & \multicolumn{4}{|c|}{ Social classes } \\
\hline & I and II & IIINM & IIIM & IV and V \\
\hline & 1451 & 1975 & 1486 & 3076 \\
\hline & 37262 & 50869 & 33980 & 72487 \\
\hline \multicolumn{5}{|l|}{ All mental health } \\
\hline Admissions* & $236(6.3)$ & $411(8.1)$ & 413 (12.2) & $875(12.1)$ \\
\hline Rate ratio 1 & 1 & $1.22(0.93$ to 1.60$)$ & $1.79(1.34$ to 2.38$)$ & 1.77 (1.38 to 2.27$)$ \\
\hline Rate ratio 2 & 1 & $1.21(0.92$ to 1.59$)$ & 1.73 (1.29 to 2.31$)$ & 1.72 (1.33 to 2.22$)$ \\
\hline Bed days $†$ & 1447 & 1586 & 2304 & 1925 \\
\hline Rate ratio 1 & 1 & 1.07 (0.62 to 1.83$)$ & 1.37 (0.77 to 2.45$)$ & $1.27(0.77$ to 2.08$)$ \\
\hline Rate ratio 2 & 1 & 1.07 (0.61 to 1.89$)$ & 1.40 (0.76 to 2.56$)$ & $1.15(0.65$ to 2.01$)$ \\
\hline \multicolumn{5}{|l|}{ Depression } \\
\hline Admissions* & $55(1.48)$ & $90(1.77)$ & $99(2.91)$ & $210(2.90)$ \\
\hline Rate ratio 1 & 1 & $1.16(0.67$ to 2.04$)$ & $1.98(1.11$ to 3.54$)$ & $1.78(1.07$ to 2.96$)$ \\
\hline Rate ratio 2 & 1 & $1.22(0.70$ to 2.13$)$ & 1.91 (1.06 to 3.43$)$ & 2.08 (1.24 to 3.50$)$ \\
\hline Bed days $†$ & 96 & 95 & 347 & 149 \\
\hline Rate ratio 1 & 1 & 1.05 (0.36 to 3.05$)$ & $5.31(1.67$ to 16.9$)$ & $1.26(0.49$ to 3.23$)$ \\
\hline Rate ratio ${ }_{2}$ & 1 & 1.18 (0.39 to 3.56$)$ & 6.42 (1.82 to 22.7$)$ & $1.67(0.55$ to 5.09$)$ \\
\hline \multicolumn{5}{|l|}{ Psychoses } \\
\hline Admissions* & $41(1.1)$ & $106(2.1)$ & $130(3.8)$ & 241 (3.3) \\
\hline Rate ratio 1 & 1 & 1.84 (1.05 to 3.23$)$ & 3.41 (1.92 to 6.06$)$ & $2.82(1.69$ to 4.72$)$ \\
\hline Rate ratio 2 & 1 & 1.69 (0.96 to 2.97$)$ & 3.32 (1.85 to 5.94$)$ & $2.63(1.53$ to 4.51$)$ \\
\hline Bed days $†$ & 147 & 378 & 571 & 385 \\
\hline Rate ratio 1 & 1 & $2.18(0.79$ to 5.98$)$ & 2.67 (0.91 to 7.81$)$ & $1.67(0.66$ to 4.25$)$ \\
\hline Rate ratio 2 & 1 & $1.73(0.55$ to 5.44$)$ & 2.35 (0.73 to 7.59$)$ & $1.17(0.39$ to 3.56$)$ \\
\hline \multicolumn{5}{|c|}{ Drug and alcohol dependence } \\
\hline Admissions* & $23(0.6)$ & $18(0.4)$ & $13(0.4)$ & $27(0.4)$ \\
\hline Rate ratio 1 & 1 & $0.46(0.13$ to 1.59$)$ & $0.85(0.22$ to 3.28$)$ & $0.44(0.14$ to 1.43$)$ \\
\hline Rate ratio 2 & 1 & 0.59 (0.19 to 1.82$)$ & $0.72(0.21$ to 2.45$)$ & $0.53(0.17$ to 1.62$)$ \\
\hline Bed days $†$ & 16 & 49 & 9 & 11 \\
\hline Rate ratio 1 & 1 & $3.68(0.40$ to 34.0$)$ & 0.88 (0.08 to 9.21$)$ & $0.46(0.06$ to 3.53$)$ \\
\hline Rate ratio 2 & 1 & 2.01 (0.14 to 29.8$)$ & 0.11 (0.01 to 2.40$)$ & $0.31(0.01$ to 7.98$)$ \\
\hline \multicolumn{5}{|c|}{ Alzheimer's and dementia } \\
\hline Admissions* & $109(2.9)$ & $201(4.0)$ & $163(4.8)$ & $381(5.3)$ \\
\hline Rate ratio 1 & 1 & $1.32(0.95$ to 1.83$)$ & 1.35 (0.96 to 1.92$)$ & $1.59(1.18$ to 2.14$)$ \\
\hline Rate ratio 2 & 1 & $1.29(0.93$ to 1.80$)$ & $1.36(0.96$ to 1.95$)$ & $1.58(1.15$ to 2.16$)$ \\
\hline Bed days & 1089 & 1004 & 1304 & 1272 \\
\hline Rate ratio 1 & 1 & $0.85(0.41$ to 1.77$)$ & 0.79 (0.35 to 1.75$)$ & $1.01(0.51$ to 1.98$)$ \\
\hline Rate ratio 2 & 1 & $0.88(0.40$ to 1.93$)$ & $0.76(0.32$ to 1.80$)$ & $0.94(0.43$ to 2.04$)$ \\
\hline $\begin{array}{l}{ }^{*} \text { Number (per } 1000 \\
\text { †Per } 1000 \text { person-ye } \\
\text { IIIM, III manual; IIINM }\end{array}$ & al; rate rc & hitio & bysic & holesterol, body \\
\hline
\end{tabular}

$1.13(95 \%$ CI 1.05 to 1.22$)$ in social classes IIINM, IIIM, IV and V, respectively, compared with social classes I and II, a pattern which again attenuated markedly with the addition of the baseline risk factors. The rate ratios of non-emergency admissions in men were 0.95 (95\% CI 0.85 to 1.05$), 0.93$ (95\% CI 0.86 to 1.01$)$ and $0.89(95 \%$ CI 0.82 to 0.97 ) in social classes IIINM, IIIM, IV and V, respectively, compared with social classes I and II and were attenuated after adjustment for risk factors.

There were contrasting patterns, therefore, between emergency and non-emergency hospital admissions for men and women, with a progressively higher rate ratio of emergency admissions and progressively lower rate ratio of non-emergency hospital admissions from social classes I and II through to social classes IV and V (figure 1).

\section{DISCUSSION}

Main results

The overall admission rates to hospital for general health conditions in this cohort are only marginally socially patterned. However, for particular diseases (such as respiratory disease, and for CVD, CHD and stroke in women), the rate ratio of hospital admissions increases from social classes I and II through to social classes IV and $\mathrm{V}$. Where the social patterning exists for particular diseases, a large proportion can be explained by a differential prevalence of baseline risk. In contrast, there is substantial social patterning for overall admissions to hospital for mental health conditions, and very markedly for psychosis, Alzheimer's and dementia in men and women, as well as for drug-related and alcohol-related 
Table 4 Number of mental health admissions and bed days by social class in men from the Renfrew and Paisley study

\begin{tabular}{|c|c|c|c|c|}
\hline \multirow{3}{*}{ Number of men } & \multicolumn{4}{|c|}{ Social classes } \\
\hline & I and II & IIINM & IIIM & IV and V \\
\hline & 1329 & 829 & 2814 & 1996 \\
\hline Person-years & 30385 & 17036 & 56966 & 38331 \\
\hline \multicolumn{5}{|l|}{ All mental health } \\
\hline Admissions* & $215(7.1)$ & $100(5.9)$ & $443(7.8)$ & 403 (10.5) \\
\hline Rate ratio 1 & 1 & 0.79 (0.53 to 1.19$)$ & $1.04(0.77$ to 1.39$)$ & 1.51 (1.11 to 2.06$)$ \\
\hline Rate ratio 2 & 1 & 0.80 (0.53 to 1.19$)$ & 0.95 (0.70 to 1.28$)$ & $1.34(0.97$ to 1.84$)$ \\
\hline Bed days $†$ & 870 & 617 & 1043 & 1874 \\
\hline Rate ratio 1 & 1 & 0.65 (0.30 to 1.42$)$ & $0.99(0.55$ to 1.79$)$ & $2.18(1.17$ to 4.08$)$ \\
\hline Rate ratio 2 & 1 & 0.72 (0.31 to 1.69$)$ & $0.83(0.44$ to 1.58$)$ & $1.79(0.90$ to 3.56$)$ \\
\hline \multicolumn{5}{|l|}{ Depression } \\
\hline Admissions* & $61(2.0)$ & $24(1.4)$ & $83(1.5)$ & $54(1.4)$ \\
\hline Rate ratio 1 & 1 & $0.71(0.32$ to 1.55$)$ & $0.63(0.36$ to 1.11$)$ & $0.67(0.36$ to 1.23$)$ \\
\hline Rate ratio 2 & 1 & 0.69 (0.31 to 1.54$)$ & $0.52(0.28$ to 0.96$)$ & $0.54(0.28$ to 1.05$)$ \\
\hline Bed days $†$ & 131 & 212 & 87 & 68 \\
\hline Rate ratio 1 & 1 & 1.96 (0.40 to 9.50$)$ & 0.69 (0.21 to 2.33$)$ & $0.56(0.16$ to 1.99$)$ \\
\hline Rate ratio 2 & 1 & 1.26 (0.18 to 8.79$)$ & $0.68(0.17$ to 2.77$)$ & 0.45 (0.09 to 2.25$)$ \\
\hline \multicolumn{5}{|l|}{ Psychoses } \\
\hline Admissions* & $32(1.1)$ & $23(1.4)$ & $96(1.7)$ & $77(2.0)$ \\
\hline Rate ratio 1 & 1 & $1.11(0.47$ to 2.60$)$ & $1.39(0.74$ to 2.63$)$ & $1.84(0.94$ to 3.60$)$ \\
\hline Rate ratio 2 & 1 & 1.18 (0.50 to 2.77$)$ & $1.28(0.67$ to 2.47$)$ & $1.78(0.89$ to 3.57$)$ \\
\hline Bed days $†$ & 75 & 104 & 190 & 630 \\
\hline Rate ratio 1 & 1 & 0.78 (0.14 to 4.42$)$ & 1.35 (0.33 to 5.49$)$ & $6.15(1.59$ to 23.7$)$ \\
\hline Rate ratio 2 & 1 & $0.91(0.14$ to 5.98$)$ & $0.99(0.22$ to 4.47$)$ & $6.42(1.01$ to 40.8$)$ \\
\hline \multicolumn{5}{|c|}{ Drug and alcohol dependence } \\
\hline Admissions* & 37 (1.2) & $13(0.8)$ & $89(1.6)$ & $108(2.8)$ \\
\hline Rate ratio 1 & 1 & $0.67(0.26$ to 1.77$)$ & $1.55(0.80$ to 3.02$)$ & $3.23(1.59$ to 6.55$)$ \\
\hline Rate ratio 2 & 1 & 0.68 (0.26 to 1.77$)$ & $1.10(0.55$ to 2.21$)$ & $1.97(0.97$ to 4.01$)$ \\
\hline Bed days $†$ & 187 & 21 & 146 & 247 \\
\hline Rate ratio 1 & 1 & $0.11(0.02$ to 0.58$)$ & $0.80(0.23$ to 2.77$)$ & $2.0(0.50$ to 7.97$)$ \\
\hline Rate ratio 2 & 1 & 0.06 (0.01 to 0.47$)$ & $0.11(0.02$ to 0.64$)$ & $0.30(0.05$ to 1.89$)$ \\
\hline \multicolumn{5}{|c|}{ Alzheimer's and dementia } \\
\hline Admissions* & 68 (2.2) & $38(2.2)$ & $176(3.1)$ & $134(3.5)$ \\
\hline Rate ratio 1 & 1 & $1.02(0.60$ to 1.74$)$ & $1.37(0.93$ to 2.03$)$ & $1.54(1.02$ to 2.32$)$ \\
\hline Rate ratio 2 & 1 & $1.02(0.59$ to 1.74$)$ & 1.47 (0.98 to 2.20$)$ & $1.63(1.07$ to 2.50$)$ \\
\hline Bed dayst & 360 & 238 & 582 & 620 \\
\hline Rate ratio 1 & 1 & 0.63 (0.19 to 2.06$)$ & $1.42(0.59$ to 3.45$)$ & $1.78(0.70$ to 4.57$)$ \\
\hline Rate ratio 2 & 1 & 0.57 (0.17 to 1.87$)$ & 1.56 (0.62 to 3.97$)$ & $1.93(0.74$ to 5.06$)$ \\
\hline
\end{tabular}

admissions in men. The overall social patterning in hospital admissions masked contrasting social patterns for emergency and non-emergency admissions. The declining rate ratio for non-emergency hospital admissions from social classes I and II through to social classes IV and $\mathrm{V}$, despite the greater prevalence of risk factors and morbidity and mortality, suggests that non-emergency admissions are not in proportion to need.

\section{Strengths and weaknesses of the study}

The socioeconomic patterning in hospital admissions is well known from routine data, but this study uses preexisting morbidity data on a variety of risk factors including blood pressure, smoking and cholesterol, which can assess the degree to which the patterning might be influenced by these risks. The data from this cohort study have the additional advantages of a very low attrition rate, up to 37 years of follow-up data and a sample which is highly representative of the communities from which it was drawn (social classes IV and V comprised $29 \%$ of the men and $39 \%$ of the women in the cohort, and $78 \%$ of the target community was recruited into the study at baseline). As the cohort was recruited in late middle age, there is unlikely to have been much subsequent social mobility (which would have created a misclassification bias).

Data on risk factors are only available for one point in time, and therefore are likely to underestimate the risk 
Table 5 Number of emergency and non-emergency general admissions by social class in men and women from the Renfrew and Paisley study

\begin{tabular}{|c|c|c|c|c|}
\hline & \multicolumn{4}{|c|}{ Social classes } \\
\hline & I and II & IIINM & IIIM & IV and V \\
\hline \multicolumn{5}{|l|}{ Women } \\
\hline Number of women & 1451 & 1975 & 1486 & 3076 \\
\hline Person-years & 37262 & 50869 & 33980 & 72487 \\
\hline \multicolumn{5}{|l|}{ Emergency admissions } \\
\hline Number of admissions & 3848 & 5590 & 3953 & 8967 \\
\hline Admissions* & 103 & 110 & 116 & 124 \\
\hline Rate ratio 1 & 1 & $1.06(0.99$ to 1.14$)$ & $1.10(1.01$ to 1.18$)$ & $1.18(1.11$ to 1.26$)$ \\
\hline Rate ratio 2 & 1 & 1.05 (0.98 to 1.13$)$ & $1.02(0.94$ to 1.10$)$ & 1.07 (1.01 to 1.15$)$ \\
\hline \multicolumn{5}{|l|}{ Non-emergency admissions } \\
\hline Number of admissions & 4760 & 6590 & 3975 & 8446 \\
\hline Admissions* & 128 & 130 & 117 & 117 \\
\hline Rate ratio 1 & 1 & $1.03(0.95$ to 1.11$)$ & $0.95(0.87$ to 1.04$)$ & $0.93(0.86$ to 1.0$)$ \\
\hline Rate ratio 2 & 1 & $1.03(0.95$ to 1.12$)$ & $0.97(0.89$ to 1.06$)$ & 0.95 (0.88 to 1.02$)$ \\
\hline \multicolumn{5}{|l|}{ Men } \\
\hline Number of men & 1329 & 829 & 2814 & 1996 \\
\hline Person-years & 30385 & 17036 & 56966 & 38331 \\
\hline \multicolumn{5}{|l|}{ Emergency admissions } \\
\hline Number of admissions & 3649 & 2161 & 7350 & 5252 \\
\hline Admissions* & 120 & 127 & 129 & 137 \\
\hline Rate ratio 1 & 1 & $1.03(0.94$ to 1.13$)$ & 1.06 (0.99 to 1.14$)$ & 1.13 (1.05 to 1.22$)$ \\
\hline Rate ratio 2 & 1 & $1.01(0.93$ to 1.11$)$ & 1.01 (0.95 to 1.09$)$ & $1.06(0.99$ to 1.14$)$ \\
\hline \multicolumn{5}{|l|}{ Non-emergency admissions } \\
\hline Number of admissions & 4722 & 2480 & 8255 & 5358 \\
\hline Admissions* & 155 & 146 & 145 & 140 \\
\hline Rate ratio 1 & 1 & $0.95(0.85$ to 1.05$)$ & $0.93(0.86$ to 1.01$)$ & 0.89 (0.82 to 0.97$)$ \\
\hline Rate ratio 2 & 1 & $0.97(0.87$ to 1.08$)$ & $0.96(0.88$ to 1.04$)$ & $0.93(0.85$ to 1.01$)$ \\
\hline
\end{tabular}

${ }^{*}$ Per 1000 person-years.

IIIM, III manual; IIINM, III non-manual; rate ratio ${ }_{1}$, adjusted for age; rate ratio ${ }_{2}$, adjusted for age, systolic blood pressure, cholesterol, body mass index, height, FEV1, angina, ischaemia on ECG, bronchitis, smoking and diabetes.

of some factors such as smoking, which have become increasingly socially patterned over time, with people from higher social classes more likely to give up. ${ }^{22}$ The social patterning of hospital admissions also varies by age, ${ }^{23}$ and therefore care should be taken to generalise only to similarly aged populations, given that the cohort was aged 45-64 years at baseline. There are also no baseline risk data for physical activity or diet, or for a wider range of risk factors that may be applicable to mental health outcomes. Although the study is internally valid, there may be limited generalisability beyond this time period and the West of Scotland-both because of the higher mortality and wider health inequalities in this population than in most other populations in western Europe during this time period ${ }^{24-26}$ and because patterns of hospital use will inevitably reflect the particular healthcare system in which they occur.

\section{Comparisons to other studies}

Social patterning in hospital admissions has been found internationally ${ }^{4-7}$ and in England and Scotland..$^{27-31}$ Adjusting for the deprivation profile and demographic characteristics of practice populations leaves a large amount of variation in hospital admissions unexplained. ${ }^{29}$
Patterns of hospital use are likely to reflect patterns of non-hospital care in their catchment areas. In the UK, the flat distribution of GPs across areas of widely contrasting socioeconomic status rations the time available to address the higher prevalence of multimorbidity in deprived areas, reducing the scope to prevent or postpone emergency admissions. ${ }^{23} 30{ }^{32}$ The lower expectations of people in deprived areas ${ }^{33}$ may also explain their less than expected use of non-emergency cardiology services. ${ }^{35}$

Healthcare needs are known to increase progressively across the socioeconomic spectrum, ${ }^{22}$ and this study shows that cardiovascular risk factors can explain a large proportion of the social patterning in hospital admissions in this study. Yet, we have shown that the populations with the greatest need (social classes IIIM, IV and V) do not consistently use hospital services in proportion to need as approximated by the baseline cardiovascular risk factors and social class. For non-emergency admissions, there is an inverse gradient between service use and health needs.

The inverse social pattern in planned, proactive and preventive work, as represented by non-emergency hospital admissions, may be related to supply factors, such as the inequitable distribution of resources, including 
Females
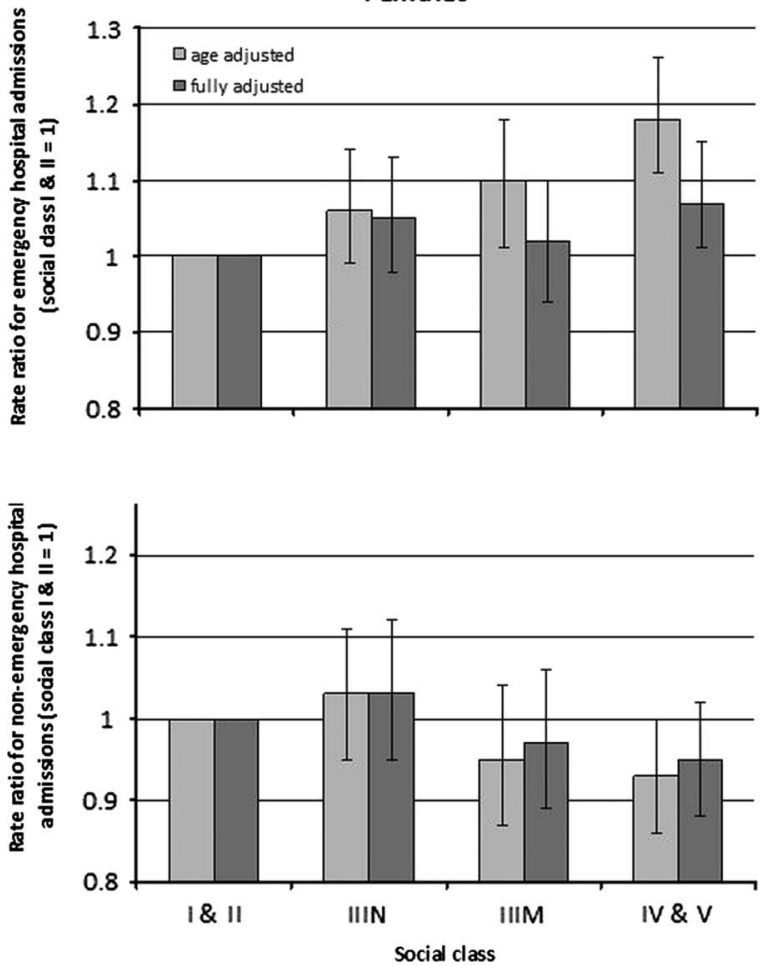

Males
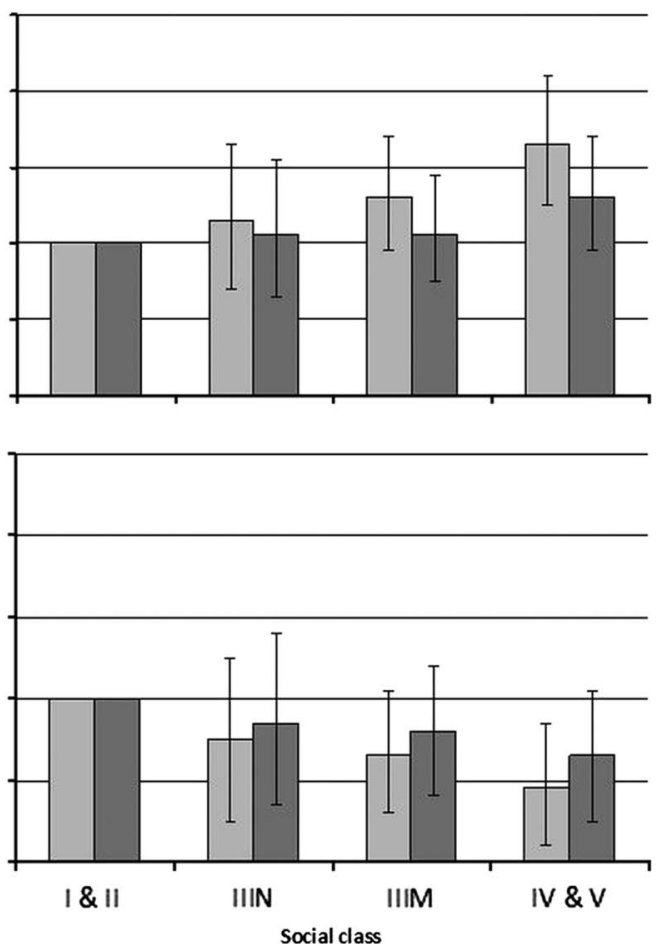

Figure 1 Patterning of emergency and non-emergency admissions to hospital by social class.

time, in primary care, but is also likely to reflect the higher prevalence and greater complexity of multimorbidity in more deprived populations, which are only captured in a limited way in the baseline risk data recorded in this study. ${ }^{23}$

\section{Implications}

The contribution that healthcare services make in reducing inequalities in health outcomes is limited by emergency hospital use not fully reflecting health needs, and non-emergency hospital use being inversely related to need. Despite the long-standing commitment of the NHS to universal healthcare access, there is still a need to monitor, explain and address inequitable patterns of healthcare use. ${ }^{36}$

\section{Conclusions}

General admissions to hospital in the West of Scotland were only marginally socially patterned, and less than would be expected on the basis of the gradient in baseline risk factors across social classes, whereas the social patterning in admissions for mental health problems was more marked. There were contrasting social patterns for emergency and non-emergency hospital admissions compared to the prevalence of baseline risk, with those with the lowest prevalence of risk factors having a higher rate ratio for non-emergency admissions. Further work is required to make the NHS more responsive to the greater needs of people in social classes IIIM, IV and V.
Acknowledgements The authors would like to thank Laurence Gruer and the peer reviewers for their helpful comments on an earlier draft of the manuscript. They would also thank the study participants, Victor Hawthorne who conducted the original Midspan studies and Pauline MacKinnon who maintains the databases.

Contributors All authors are members of the NHS Health Scotland and Glasgow University Midspan research group. CH performed the analysis. GMC drafted the manuscript. All authors helped plan the study, evolved the analysis plans, interpreted the data, critically revised successive drafts of the manuscript and approved the final version of the manuscript.

Funding None.

Competing interests None.

Ethics approval The data collection for this study predated ethics committees.

Provenance and peer review Not commissioned; externally peer reviewed.

Data sharing statement No additional data are available.

Open Access This is an Open Access article distributed in accordance with the Creative Commons Attribution Non Commercial (CC BY-NC 3.0) license, which permits others to distribute, remix, adapt, build upon this work noncommercially, and license their derivative works on different terms, provided the original work is properly cited and the use is non-commercial. See: http:// creativecommons.org/licenses/by-nc/3.0/

\section{REFERENCES}

1. Hart JT. The inverse care law. Lancet 1971;297:405-12.

2. Stevens A, Gillam S. Needs assessment: from theory to practice. BMJ 1998;316:1448.

3. Peen J, Dekker J. Social deprivation and psychiatric service use for different diagnostic groups. Soc Sci Med 2001;53:1-8.

4. Barnett $R$, Lauer $G$. Urban deprivation and public hospital admissions in Christchurch, New Zealand, 1990-1997. Health Soc Care Community 2003;11:299-313. 
5. Brameld KJ, Holman CDJ. The use of end-quintile comparisons to identify under-servicing of the poor and over-servicing of the rich: a longitudinal study describing the effect of socioeconomic status on healthcare. BMC Health Serv Res 2005;5:61.

6. Carlsen F, Grytten J, Kjelvik J, et al. Better primary physician services lead to fewer hospital admissions. Eur J Health Econ 2007;8:17-24.

7. Reid FDA, Cook DG, Majeed A. Explaining variation in hospital admission rates between general practices: cross sectional study. BMJ 1999;319:98-103.

8. Antonelli-Incalzil R, Ancona C, Forastiere F, et al. Socioeconomic status and hospitalization in the very old: a retrospective study. BMC Public Health 2007;7:227.

9. Landi F, Onder G, Cesar M, et al. Comorbidity and social factors predicted hospitalization in frail elderly patients. J Clin Epidemiol 2004;57:832-6.

10. Schifano P, Marinacci C, Cesaroni G, et al. Temporal and geographic heterogeneity of the association between socioeconomic position and hospitalisation in Italy: an income based indicator. Int $J$ Equity Health 2009;8:33.

11. Glazier RH, Badley EM, Gilbert JE, et al. The nature of increased hospital use in poor neighbourhoods: findings from a Canadian inner city. Can J Public Health 2000;91:268-73.

12. Asada $\mathrm{Y}, \mathrm{Kephart} \mathrm{G}$. Equity in health services use and intensity of use in Canada. BMC Health Serv Res 2007;7:41.

13. Liao Y, McGee DL, Kaufman JS, et al. Socioeconomic status and morbidity in the last years of life. Am J Public Health 1999;89:569-72.

14. Taylor CB, Ahn D, Winkleby MA. Neighborhood and individual socioeconomic determinants of hospitalization. Am J Prev Med 2006;31:127-34.

15. Davies CA, Leyland AH. Trends and inequalities in short-term acute myocardial infarction case fatality in Scotland, 1988-2004. Popul Health Metr 2010;8:33.

16. Leyland $\mathrm{AH}$, Dundas $\mathrm{R}$, McLoone $\mathrm{P}$, et al. Inequalities in mortality in Scotland, 1981-2001. MRC Social and Public Health Sciences Unit Occasional Paper no. 16. Glasgow: MRC Social and Public Health Sciences Unit, 2007.

17. Hawthorne VM, Watt GCM, Hart CL, et al. Cardiorespiratory disease in men and women in urban Scotland: baseline characteristics of the Renfrew/Paisley (Midspan) study population. Scott Med J 1995;40:102-7.

18. Hart CL, Watt GCM, Davey Smith G, et al. Pre-existing ischaemic heart disease and ischaemic heart disease mortality in women compared with men. Int J Epidemiol 1997;26:508-15.

19. General Register Office. Classification of occupations 1966. London: HMSO, 1966:1-148.

20. Davey Smith G, Hart C, Watt G, et al. Individual social class, area-based deprivation, cardiovascular disease risk factors, and mortality: the Renfrew and Paisley study. J Epidemiol Community Health 1998:52:399-405.

21. Kendrick SW, Clarke JA. The Scottish Record Linkage System. Health Bull (Edinb) 1993;51:72-9.
22. Ferrie JE, Shipley MJ, Davey Smith G, et al. Change in health inequalities among British civil servants: the Whitehall II study. J Epidemiol Community Health 2002;56:922-6.

23. Barnett $\mathrm{K}$, Mercer SW, Norbury M, et al. Epidemiology of multimorbidity and implications for health care, research, and medical education: a cross-sectional study. Lancet 2012; 380:37-43.

24. Leon D, Morton S, Cannegieter S, et al. Understanding the health of Scotland's population in an international context: a review of current approaches, knowledge and recommendations for new research directions. London: London School of Hygiene and Tropical Medicine and Public Health Institute for Scotland, 2003. http://www. scotpho.org.uk/home/Comparativehealth/InternationalComparisons/ int mortality comparisons.asp (accessed 20 Apr 2010).

25. Whyte B. Scottish mortality in a European context 1950-2000: an analysis of comparative mortality trends. Edinburgh Scottish Public Health Observatory, 2007. http://www.scotpho.org.uk/ nmsruntime/saveasdialog.asp? IID=3591\&sID=3079 (accessed 20 Apr 2010).

26. McCartney G, Walsh D, Whyte B, et al. Has Scotland always been the 'sick man' of Europe? Eur J Public Health 2012;22:756-60

27. Bernard S, Smith LK. Emergency admissions of older people to hospital: a link with material deprivation. J Public Health Med 1998;20:97-101.

28. West J, Hippisley-Cox J, Coupland CAC et al. Do rates of hospital admission for falls and hip fracture in elderly people vary by socio-economic status? Public Health 2004;118:576-81.

29. Blatchford O, Capewell S, Murray S, et al. Emergency medical admissions in Glasgow: general practices vary despite adjustment for age, sex, and deprivation. Br J Gen Pract 1999;49:551-4.

30. Mackay D, Sutton M, Watt G. Deprivation and volunteering by general practices: cross sectional analysis of a national primary care system. BMJ 2005;331:1449-51.

31. Purdy S, Griffin T, Salisbury C, et al. Emergency admissions for coronary heart disease: a cross-sectional study of general practice, population and hospital factors in England. Public Health 2011;125:46-54.

32. Payne RA, Abel GA, Guthrie B, et al. The effect of physical multimorbidity, mental health conditions and socioeconomic deprivation on unplanned admissions to hospital: a retrospective cohort study. CMAJ 2013;185:E221-8.

33. Dixon-Woods M, Kirk D, Agarwal S, et al. Conducting a critical interpretative synthesis of the literature on access to health care by vulnerable groups. BMC Med Res Methodol 2006;6:35

34. Mackenzie M, Conway E, Hastings A, et al. Is 'candidacy' a useful concept for understanding journeys through public services? A critical interpretative literature synthesis. Soc Policy Adm 2012 Doi: 10.1111/j.1467-9515.2012.00864.x

35. Richards HM, Reid ME, Watt GCM. Socioeconomic variations in responses to chest pain: qualitative study. BMJ 2002;324:1308.

36. Watt G. The inverse care law today. Lancet 2002;360:252-4. 